\title{
GOOGLE CAR TAKES THE TEST
}

\author{
The drive of your life.
}

\section{BY NORMAN SPINRAD}

W

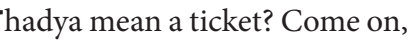
I'm a cop too, ain't I? Well almost, so I'm only a driving-test officer, but I got the cap and the uniform, don't I? And I wasn't driving this damn thing, now, was I?

Just my job, pal. Not my idea that Google Cars should have to have driving licences to hit the road like you and me. Good or bad idea, it's the law, and we didn't make it, did we? My job is to test the thing, pass or fail, and this sucker didn't, and your job is to write a ticket, or yeah, in this case, a whole padfull, if a driver plays wise guy with the rules of the road.

But you can't ticket me, I wasn't driving, not for a minute. Take a good look, pal. No steering wheel, no brake pedal, no accelerator, no speedometer, no nothing. Yeah, you gotta write up a tonne of tickets, but you gotta ticket Google.

I wasn't exactly against these driverless cars before, in my line of duty, you spend your working day being driven around by so-called human drivers half of which just manage to pass the road test and the other half who don't but usually don't quite get you killed.

Which is why we got a reputation for looking for ways to fail you, especially towards the end of the shift, I mean, officer, wouldn't you? And seeing as how I see myself as a guardian of the safety of the road from what shouldn't be allowed to barrel along down it, I'm not against making these robots pass the test too.

Okay, I gotta admit I had it in for the thing, especially when it's last on the line at the end of the day, looks like one of those cartoon cars out of that Disney movie, what can I tell you, I got three kids, and I just can't take any more cutsy-poo than I have to, can you?

It's passed the written test or it wouldn't be on the line, how could it not since it's really Google, and Google knows everything.

It works on voice command, so I tell it

$\rightarrow$ NATURE.COM

Follow Futures:

@ @NatureFutures

f go.nature.com $/ \mathrm{mtoodm}$ to open up and it lets me in. I tell it to close, but it won't do that until I buckle in, fair enough. Not every test car comes equipped with dual steering wheels and peddles, it's unfortunately not mandatory, and you get used to it. But when it gets through to me that this thing doesn't have any manual controls at all I gotta admit it freaks me out a bit. However, it's the end of the shift, and the job is the job, what are you gonna do, so...

"Go straight!"

It does. But the Harley is following us and the Google Car keeps to the speed limit like a good little citizen, which, as you gotta know, officer, is not a constraint on the Hell's Angel.

"Don't let that bike catch up with us!"

Nothing happens.

"Uh ... emergency override! Do what it takes!"

Well the Google Car does. But within the letter of the law. Doesn't break the speed limit. Doesn't make illegal turns. What it does is find itself a one-way street jammed with crawling early rushhour traffic, no sweat for Google GPS in LA, and it bobs and weaves through it at the exact speed limit with inches to spare, to the point where I gotta close my eyes to keep from having a heart attack.

When I open them, the Harley is nowhere in sight, but the Google Car is still doing it - up a freeway on-ramp!

Should have told it what? In the middle of a crowded freeway on-ramp? Stop? Turn back? Wait your turn?

I tell it to pull away from the kerb, which it does, but it immediately loses points for not looking back over its shoulder and handsignalling, which, having no hands, head or shoulder, it can't, but those are the rules, dumb as they may be in modern times.

Keeps good distance front and back in the straightaways, doesn't try to race through yellow lights, turns right from the right lane and left from the left and all, maintains speed limits exactly like a prissy sissy, which is what you're supposed to do on the test. But keeps losing points for not hand-signalling so I've got plenty enough to fail it with even before the parking test.

So I pick a space between a Toyota and a VW with maybe six inches front and back to squeeze into, this I gotta see...

"Pull over and park here."

Which, like magic, it does!

Only it cuts off a Hell's Angel on his Harley doing it, and this dude is not amused, starts dismounting with his engine still running, blood in his eyes, and a big monkey wrench in his hand.

"Get us out of here right now!"

It pulls out sideways, but just sits there.
What would you have said, wise guy?

Whatsa matter, officer, cat got your tongue? Okay, okay, I shouldn't have said what I did, and if I hadn't maybe, just maybe, I wouldn't have found myself trapped in a socalled smartcar jigging and jagging at the legal speed limit through three lanes of traffic going 10 m.p.h. faster through the desert with a dozen Highway Patrol cars tailing it and trying to figure out what in hell to do about it until its battery finally ran down.

I didn't even realize it wasn't just inside my head when I screamed it. In fact, I think the first part was just in my head ... Google, Schmoogle, these things...

What did I tell the Google Car out loud? Tell me you wouldn't have said it, officer!

"Drive like a drunken bank robber with a sack full of hundred dollar bills on his way to Las Vegas!" -

Norman Spinrad has now been publishing novels in English for an actual half-century. His latest publication in English is the pamphlet Raising Hell. His latest novel has just been published in French as Police Du Peuple. 